\title{
Gambaran Status Gingiva Pada Penderita Diabetes Melitus Tipe 2 Di Rumah Sakit Umum GMIM Pancaran Kasih Manado
}

\author{
${ }^{1}$ Olyvia Octaviany Monoarfa \\ ${ }^{2}$ Karel Pandelaki \\ ${ }^{3}$ Christy N. Mintjelungan
}

\author{
${ }^{1}$ Kandidat Skripsi Program Studi Pendidikan Dokter Gigi Fakultas Kedokteran Universitas \\ Sam Ratulangi Manado \\ ${ }^{2}$ Bagian Penyakit Dalam Fakultas Kedokteran Universitas Sam Ratulangi Manado \\ ${ }^{3}$ Program Studi Pendidikan Dokter Gigi Fakultas Kedokteran \\ Universitas Sam Ratulangi Manado \\ E-mail : olyvia.monoarfa@gmail.com
}

\begin{abstract}
Diabetes Mellitus (DM) is a metabolic disease group with the characteristic blood glucose levels than normal (hyperglycemia) that occurs because abnormalities in insulin secretion, insulin recognized when payable disorders, or combination of both. Regular blood glucose levels cause patients uncontrolled type 2 diabetes are at greater risk for experiencing problems of oral health, including gingivitis. Purpose of this research was to know the description of gingival status in patients of type 2 diabetes at RSU GMIM Pancaran Kasih Manado. This research is an observational descriptive with cross sectional study approach. The research population is all patients of type 2 diabetes outpatient clinic Interna RSU GMIM Pancaran Kasih Manado in September 2014. The research method is by using a Consecutive sampling with a sample of 100 people. The result of this research showed that the gingival status in patients of type 2 diabetes calculated based gingival index that most occur severe gingivitis was 45 respondents (45\%). The gingival status that showed the severe gingivitis in patients of type 2 diabetes based on age 17 respondents $(48,6 \%)$ in the age range of 51-60 years old, based on gender that most occur in women 27 respondents $(49,1 \%)$, based on duration of suffering 25 respondents $(55,6 \%)$ in the age range $>10$ years, and based on blood glucose control ( $\mathrm{HbA1c}$ ) that most numerous in patients with poor blood glucose 30 respondents $(60 \%)$. Conclusion: The gingival status in patients of type 2 diabetes most occur severe gingivitis, and recommended in patients of type 2 diabetes to improve their healthy lifestyle in order to normalize blood glucose levels so as to reduce the occurrence of diabetes, more attention and maintain oral hygiene, especially the gingival health.
\end{abstract}

Keywords: gingival status, patients of type 2 diabetes.

\begin{abstract}
Abstrak: Diabetes Melitus (DM) adalah suatu kelompok penyakit metabolik dengan karakteristik kadar glukosa darah yang melebihi normal (hiperglikemia) yang terjadi karena kelainan sekresi insulin, gangguan kerja insulin, ataupun kombinasi dari keduanya. Kadar gula darah yang tidak terkontrol menyebabkan penderita DM tipe 2 beresiko lebih tinggi mengalami masalah kesehatan mulut, termasuk gingivitis. Penelitian ini bertujuan untuk mengetahui gambaran status gingiva pada penderita Diabetes Melitus tipe 2 di Rumah Sakit Umum GMIM Pancaran Kasih Manado. Penelitian ini merupakan penelitian deskriptif observasional dengan pendekatan cross sectional study. Populasi penelitian yaitu seluruh pasien DM tipe 2 rawat jalan di Poliklinik Interna Rumah Sakit Umum GMIM Pancaran Kasih Manado pada bulan September 2014. Metode penelitian yaitu Consecutive sampling dengan sampel penelitian berjumlah 100 orang. Hasil penelitian menunjukkan bahwa status gingiva yang dihitung berdasarkan indeks gingiva paling banyak menunjukkan gingivitis berat 45 subjek penelitian $(45 \%)$. Status Gingiva berdasarkan umur paling banyak 17 subjek penelitian $(48,6 \%)$ pada rentang umur 51-60 tahun, berdasarkan jenis kelamin paling banyak pada perempuan 27 subjek penelitian $(49,1 \%)$, berdasarkan lamanya menderita
\end{abstract}


paling banyak selama $>10$ tahun 25 subjek penelitian $(55,6 \%)$, dan berdasarkan kontrol gula darah (HbA1c) paling banyak pada pasien dengan kontrol gula darah buruk (>9\%) 30 subjek penelitian (60\%). Simpulan: Penderita DM tipe 2 di Rumah Sakit Umum GMIM Pancaran Kasih Manado paling banyak mengalami gingivitis berat, serta disarankan bagi penderita agar lebih meningkatkan pola hidup sehat guna menormalkan kadar glukosa darah sehingga dapat mengurangi terjadinya diabetes, lebih memperhatikan dan menjaga kebersihan gigi dan mulut, terutama kesehatan gingivanya.

Kata kunci: status gingiva, penderita diabetes melitus tipe 2

Diabetes Melitus (DM) atau yang lebih dikenal oleh masyarakat awam dengan istilah penyakit kencing manis merupakan suatu keadaan penyakit degeneratif (menua) yang dapat disertai komplikasi kronik maupun akut ${ }^{1}$ dan merupakan salah satu penyakit yang tidak menular.

Berdasarkan penelitian epidemiologis di Indonesia didapatkan prevalensi DM sebesar 1,5-2,3 \% pada penduduk usia >15 tahun, laporan hasil penelitian dari berbagai daerah di Indonesia menunjukkan sebaran prevalensi DM tipe 2 antara $0,8 \%$ di Tanah Toraja sampai $6,1 \%$ didapatkan di Manado ${ }^{3}$ dan berdasarkan laporan hasil Riset Kesehatan Dasar (RISKESDAS) tahun 2011 oleh Departemen Kesehatan menunjukkan bahwa prevalensi DM di Sulawesi Utara sebesar 8,1\%. ${ }^{4}$ Pada tahun 2007 Ketua Persatuan Diabetes Indonesia (PERSADIA) yaitu Prof. Sidartawan, SpPD mengemukakan bahwa sebagian besar penderita diabetes di Indonesia mengidap DM tipe 2. Diabetes tipe ini secara umum biasa dikaitkan dengan usia lanjut, obesitas, dan gaya hidup yang tidak sehat (pola makan tinggi lemak, dan jarang berolah raga). ${ }^{5}$

Pemantauan status metabolik pasien DM merupakan hal yang penting. Maka dari itu dalam pengelolaannya dibutuhkan kontrol gula darah secara intensif. Sejauh ini parameter kontrol gula darah jangka panjang yang digunakan yaitu HbA1c. ${ }^{6}$ Diabetes Melitus (DM) merupakan salah satu penyakit sistemik yang bermanifestasi dalam rongga mulut. Hal ini dapat terjadi khususnya pada penderita DM tipe 2. Diabetes yang tidak terkontrol mengganggu sel darah putih dan sel-sel imun seperti neutrofil, monosit, dan makrofag yang berfungsi untuk pertahanan tubuh. Hal ini menyebabkan kemampuan tubuh untuk melawan bakteri menjadi menurun dan penderita menjadi lebih rentan terhadap infeksi. Pada penderita DM terjadi peningkatan jumlah bakteri dalam rongga mulut sehingga menyebabkan adanya kelainan pada jaringan periodontal termasuk gingiva. $5,7,8,9$

Beberapa penelitian sebelumnya menyatakan bahwa diabetes menjadi salah satu faktor risiko prevalensi gingivitis. ${ }^{10} \mathrm{Hal}$ ini juga diperkuat dengan penelitian sebelumnya oleh Windiyarti (2003) di Rumah Sakit Umum Daerah Banjarnegara dimana prevalensi gingivitis pada penderita DM tipe 2 sebesar 96,7\%. ${ }^{11}$ Tingginya prevalensi gingivitis pada penderita DM tipe 2 membuktikan bahwa penderita DM rentan terhadap gingivitis. Tahun 1963 oleh Loe dan Silness, diperkenalkan indeks gingiva sebagai cara untuk mengetahui status kesehatan jaringan gingiva dan untuk melihat keradangan pada gingiva. $^{12}$

Mengingat pentingnya kesehatan gigi dan mulut khususnya status gingiva bagi penderita DM tipe 2, serta berdasarkan pengamatan bahwa sebagian besar belum ada penelitian sebelumnya tentang gambaran status gingiva di rumah sakit tipe $\mathrm{C}$ seperti Rumah Sakit Umum GMIM Pancaran Kasih Manado, maka peneliti merasa tertarik untuk melakukan penelitian di Rumah Sakit Umum GMIM Pancaran Kasih Manado.

\section{METODE PENELITIAN}

Jenis penelitian yang digunakan yaitu penelitian deskriptif observasional dengan menggunakan pendekatan cross sectional study. Penelitian ini dilakukan di Poliklinik Interna Rumah Sakit Umum GMIM Pancaran Kasih Manado dan dilaksanakan pada bulan September 2014. Populasi dalam 
penelitian ini yaitu seluruh pasien DM tipe 2 yang dirawat jalan di Poliklinik Interna Rumah Sakit Umum GMIM Pancaran Kasih Manado pada bulan September 2014. Metode pengambilan sampel yaitu consecutive sampling. Kriteria inklusi pada penelitian ini yaitu pasien yang bersedia dan sukarela dijadikan subjek dalam penelitian ini dengan menandatangani informed consent, pasien yang dapat membuka mulut dengan baik, pasien yang bersifat kooperatif dan dapat berkomunikasi dengan baik. Kriteria eksklusi yaitu pasien yang kehilangan semua gigi indeks, pasien yang menggunakan protesa, pasien yang dalam kondisi hamil, dan pasien yang sedang menjalankan kemoterapi.

Dalam penelitian ini digunakan indeks gingiva untuk menilai derajat keparahan inflamasi gingiva dengan melakukan pengukuran gingiva pada sisi indeks, yaitu mesial, bukal/labial, distal, dan lingual/palatal elemen 16, 21, 24, 36, 41, dan 44, kemudian diukur berdasarkan indeks gingiva menurut Loe dan Silness dengan kategori : skor $0,1-1,0=$ gingivitis ringan, $1,1-2,0=$ gingivitis sedang, $2,1-3,0=$ gingivitis berat. Kontrol gula darah dari setiap pasien DM tipe 2 dilihat berdasarkan HbA1c dengan kategori : $<7 \%=$ baik, $7-$ $9 \%=$ sedang, $>9 \%=$ buruk .

\section{HASIL PENELITIAN}

Hasil penelitian tentang Gambaran status gingiva pada penderita diabetes melitus tipe 2 di rumah sakit umum GMIM Pancaran Kasih Manado dapat dilihat pada Tabel 1-9.

Tabel 1 menunjukkan dari total 100 subjek penelitian yang dilihat berdasarkan umur paling banyak terdapat pada kelompok umur 51 - 60 tahun dengan jumlah 35 subjek penelitian $(35 \%)$, diikuti kelompok umur 61-70 tahun dengan jumlah 30 subjek penelitian (30\%), kemudian kelompok umur 41-50 tahun dengan jumlah 20 subjek penelitian (20\%), lalu kelompok umur 71-80 tahun dengan jumlah 9 subjek penelitian ( 9 $\%)$, dan paling sedikit terdapat pada kelompok umur 31 - 40 tahun berjumlah 6 subjek penelitian $(6 \%)$.

Tabel 1. Distribusi subjek penelitian berdasarkan umur

\begin{tabular}{cll}
\hline Umur (tahun) & $\mathrm{n}$ & $\%$ \\
\hline $31-40$ & 6 & 6 \\
$41-50$ & 20 & 20 \\
$51-60$ & 35 & 35 \\
& & \\
$61-70$ & 30 & 30 \\
$71-80$ & 9 & 9 \\
\hline Total & 100 & 100 \\
\hline
\end{tabular}

Tabel 2. Distribusi subjek penelitian berdasarkan jenis kelamin

\begin{tabular}{lcc}
\hline Jenis Kelamin & $\mathrm{n}$ & $\%$ \\
\hline Laki-laki & 45 & 45 \\
Perempuan & 55 & 55 \\
\hline Total & 100 & 100 \\
\hline
\end{tabular}

Tabel 2 menunjukkan dari total 100 subjek penelitian diketahui bahwa subjek penelitian yang paling banyak yaitu perempuan dengan jumlah 55 subjek penelitian (55\%), dan laki-laki berjumlah 45 subjek penelitian (45\%).

Tabel 3. Distribusi subjek penelitian berdasarkan lamanya menderita DM tipe 2

\begin{tabular}{crr}
\hline $\begin{array}{l}\text { Lamanya menderita } \\
\text { DM tipe 2 }(\text { tahun })\end{array}$ & $\mathrm{n}$ & $\%$ \\
\hline$<5$ & 15 & 15 \\
$5-10$ & 40 & 40 \\
$>10$ & 45 & 45 \\
\hline Total & 100 & 100 \\
\hline
\end{tabular}

Tabel 3 menunjukkan dari total 100 subjek penelitian diketahui bahwa subjek penelitian yang menderita DM tipe 2 selama > 10 tahun memiliki jumlah terbanyak yaitu 45 subjek penelitian (45\%), kemudian diikuti dengan subjek penelitian yang menderita DM tipe 2 selama 5-10 tahun berjumlah 40 subjek penelitian (40\%), dan yang paling sedikit yaitu subjek penelitian yang menderita DM tipe 2 selama $<5$ tahun berjumlah 15 subjek penelitian $(15 \%)$. 
Tabel 4. Distribusi subjek penelitian berdasarkan kontrol gula darah (HbA1c)

\begin{tabular}{ccc}
\hline Kontrol Gula Darah (HbA1C) & $\mathrm{n}$ & $\%$ \\
\hline Baik (<7\%) & 10 & 10 \\
Sedang (7-9\%) & 40 & 40 \\
Buruk (>9\%) & 50 & 50 \\
Total & 100 & 100 \\
\hline
\end{tabular}

Tabel 4 menunjukkan dari total 100 subjek penelitian diketahui bahwa subjek penelitian yang memiliki kontrol gula darah buruk (>9\%) berjumlah 50 subjek penelitian (50 $\%)$, subjek penelitian yang memiliki kontrol gula darah sedang (7-9\%) berjumlah 40 subjek penelitian (40\%), dan subjek penelitian yang memiliki kontrol gula darah baik $(<7 \%)$ berjumlah 10 subjek penelitian $(10 \%)$

Tabel 5. Distribusi status gingiva berdasarkan indeks gingiva

\begin{tabular}{lll}
\hline Kategori & $\mathrm{n}$ & $\%$ \\
\hline Ringan & 15 & 15 \\
Sedang & 40 & 40 \\
Berat & 45 & 45 \\
\hline Total & 100 & 100 \\
\hline
\end{tabular}

Tabel 5 menunjukkan dari total 100 subjek penelitian diketahui bahwa yang mengalami gingivitis ringan yaitu berjumlah 15 subjek penelitian $(15 \%)$, yang mengalami gingivitis sedang yaitu berjumlah 40 subjek penelitian ( 40 $\%)$, dan yang mengalami gingivitis berat yaitu berjumlah 45 subjek penelitian (45 \%).

Tabel 6. Distribusi status gingiva berdasarkan umur

\begin{tabular}{|c|c|c|c|c|c|c|c|c|}
\hline \multirow{3}{*}{ Umur (tahun) } & \multicolumn{6}{|c|}{ Status Gingiva } & \multirow{2}{*}{\multicolumn{2}{|c|}{ Jumlah }} \\
\hline & \multicolumn{2}{|c|}{ Ringan } & \multicolumn{2}{|c|}{ Sedang } & \multicolumn{2}{|c|}{ Berat } & & \\
\hline & $\mathrm{n}$ & $\%$ & $\mathrm{n}$ & $\%$ & $\mathrm{n}$ & $\%$ & $\mathrm{n}$ & $\%$ \\
\hline $31-40$ & 4 & 66,6 & 1 & 16,7 & 1 & 16,7 & 6 & 100 \\
\hline $41-50$ & 3 & 15 & 8 & 40 & 9 & 45 & 20 & 100 \\
\hline $51-60$ & 1 & 2,8 & 17 & 48,6 & 17 & 48,6 & 35 & 100 \\
\hline $61-70$ & 4 & 13,3 & 12 & 40 & 14 & 46,7 & 30 & 100 \\
\hline \multirow[t]{2}{*}{$71-80$} & 3 & 33,3 & 2 & 22,2 & 4 & 44,5 & 9 & 100 \\
\hline & & & & & & Total & 100 & 100 \\
\hline
\end{tabular}

Tabel 6 menunjukkan bahwa yang paling banyak mengalami gingivitis sedang dan berat yaitu pada rentang umur $51-60$ tahun masingmasing berjumlah 17 subjek penelitian $(48,6 \%)$, serta yang paling banyak mengalami gingivitis ringan yaitu pada rentang umur $31-40$ tahun berjumlah 4 subjek penelitian $(66,6 \%)$.

Tabel 7. Distribusi status gingiva berdasarkan jenis kelamin

\begin{tabular}{|c|c|c|c|c|c|c|c|c|}
\hline \multirow{3}{*}{ Jenis Kelamin } & \multicolumn{6}{|c|}{ Status Gingiva } & \multirow{2}{*}{\multicolumn{2}{|c|}{ Jumlah }} \\
\hline & \multicolumn{2}{|c|}{ Ringan } & \multicolumn{2}{|c|}{ Sedang } & \multicolumn{2}{|c|}{ Berat } & & \\
\hline & $\mathrm{n}$ & $\%$ & $\mathrm{n}$ & $\%$ & $\mathrm{n}$ & $\%$ & $\mathrm{n}$ & $\%$ \\
\hline Laki-laki & 10 & 22,2 & 17 & 37,8 & 18 & 40 & 45 & 100 \\
\hline Perempuan & 5 & 9,1 & 23 & 41,8 & 27 & 49,1 & 55 & 100 \\
\hline
\end{tabular}


Tabel 7 menunjukkan bahwa subjek penelitian berjenis kelamin perempuan paling banyak mengalami gingivitis sedang dan berat yaitu masing - masing dengan jumlah 23 subjek penelitian $(41,8 \%)$, dan 27 subjek penelitian $(49,1 \%)$, kemudian diikuti subjek penelitian laki - laki yang mengalami gingivitis sedang dan berat yaitu masing - masing dengan jumlah 17 subjek penelitian (37,8 \%), dan 18 subjek penelitian $(40 \%)$ serta gingivitis ringan lebih banyak terjadi pada laki - laki yaitu dengan jumlah 10 subjek penelitian (22,2 \%) daripada perempuan yaitu dengan jumlah 5 subjek penelitian $(9,1 \%)$.

Tabel 8. Distribusi status gingiva berdasarkan lamanya menderita DM tipe 2

\begin{tabular}{|c|c|c|c|c|c|c|c|c|}
\hline \multirow{3}{*}{$\begin{array}{l}\text { Lamanya menderita } \\
\text { DM tipe } 2\end{array}$} & \multicolumn{4}{|c|}{ Status Gingiva } & & & & \\
\hline & \multicolumn{2}{|c|}{ Ringan } & \multicolumn{2}{|c|}{ Sedang } & \multicolumn{2}{|c|}{ Berat } & \multicolumn{2}{|c|}{ Jumlah } \\
\hline & $\mathrm{n}$ & $\%$ & $\mathrm{n}$ & $\%$ & $\mathrm{n}$ & $\%$ & $\mathrm{n}$ & $\%$ \\
\hline$<5$ & 10 & 66,7 & 5 & 33,3 & 0 & 0 & 15 & 100 \\
\hline $5-10$ & 5 & 12,5 & 15 & 37,5 & 20 & 50 & 40 & 100 \\
\hline$>10$ & 0 & 0 & 20 & 44,4 & 25 & 55,6 & 45 & 100 \\
\hline & & & & & & Total & 100 & 100 \\
\hline
\end{tabular}

Tabel 8 menunjukkan bahwa gingivitis sedang dan berat paling banyak dialami oleh subjek penelitian yang menderita DM tipe 2 selama $>10$ tahun dengan jumlah masing masing 20 subjek penelitian $(44,4 \%)$, dan 25 subjek penelitian $(55,6 \%)$, serta gingivitis ringan paling banyak dialami oleh subjek penelitian yang menderita DM tipe 2 selama $<5$ tahun yaitu dengan jumlah 10 subjek penelitian $(66,7 \%)$.

Tabel 9. Distribusi status gingiva berdasarkan kontrol gula darah ( $\mathrm{HbA1c}$ )

\begin{tabular}{|c|c|c|c|c|c|c|c|c|}
\hline \multirow{3}{*}{$\begin{array}{l}\text { Kontrol Gula Darah } \\
\text { ( HbA1c ) }\end{array}$} & \multicolumn{6}{|c|}{ Status Gingiva } & \multirow{2}{*}{\multicolumn{2}{|c|}{ Jumlah }} \\
\hline & \multicolumn{2}{|c|}{ Ringan } & \multicolumn{2}{|c|}{ Sedang } & \multicolumn{2}{|c|}{ Berat } & & \\
\hline & $\mathrm{n}$ & $\%$ & $\mathrm{n}$ & $\%$ & $\mathrm{n}$ & $\%$ & $\mathrm{n}$ & $\%$ \\
\hline Baik $\quad(<7 \%)$ & 10 & 100 & 0 & 0 & 0 & 0 & 10 & 100 \\
\hline Sedang $(7-9 \%)$ & 3 & 7,5 & 22 & 55 & 15 & 37,5 & 40 & 100 \\
\hline Buruk $(>9 \%)$ & 2 & 4 & 18 & 36 & 30 & 60 & 50 & 100 \\
\hline & & & & & & Total & 100 & 100 \\
\hline
\end{tabular}

Tabel 9 menunjukkan bahwa gingivitis berat paling banyak terdapat pada subjek penelitian dengan kontrol gula darah (HbA1c) buruk (>9\%) yaitu dengan jumlah 30 subjek penelitian (60\%), kemudian gingivitis sedang paling banyak terdapat pada subjek penelitian dengan kontrol gula darah (HbA1c) sedang (7-9\%) yaitu dengan jumlah 22 subjek penelitian (55\%), serta gingivitis ringan paling banyak terdapat pada subjek penelitian dengan kontrol gula darah (HbA1c) baik $(<7 \%)$ yaitu dengan jumlah 10 subjek penelitian $(100 \%)$.

\section{BAHASAN}

Berdasarkan hasil didapatkan status gingiva berdasarkan indeks gingiva yang termasuk kategori gingivitis berat sebanyak 45 subjek penelitian (45\%), hasil ini sejalan dengan penelitian yang dilakukan oleh Kartika, yang juga mendapatkan responden DM tipe 2 yang mengalami gingivitis berat, namun jauh lebih sedikit yaitu sebanyak 7 responden $(25,9 \%) .{ }^{13}$ Kategori gingivitis berat ini lebih rentan terjadi pada umur $>40$ tahun serta paling banyak dialami oleh perempuan, hasil ini sejalan dengan penelitian yang dilakukan oleh Awad pada 
tahun 2012 yang juga mendapatkan status gingiva dengan kategori gingivitis berat dengan jumlah terbanyak ditemui pada perempuan dengan umur lebih dari 40 tahun $^{14}$.

Sehubungan dengan hasil penelitian yang menunjukkan bahwa yang paling banyak ditemui yaitu gingivitis atau inflamasi gingiva berat, hal ini juga ditunjukkan oleh hasil penelitian yang dilakukan Novia Winardi pada tahun 2011, menyatakan bahwa prediktor yang terlihat signifikan pada penderita DM tipe 2 yaitu adanya perdarahan pada saat probing atau adanya penyakit gingiva yang parah. Dengan kata lain, risiko memiliki gingivitis yang parah adalah dua kali lipat dibandingkan dengan penderita DM tipe $1^{15}$.

Selanjutnya hasil pemeriksaan status gingiva berdasarkan lamanya menderita DM tipe 2 yang paling banyak ditemui yaitu penderita yang mengalami DM tipe 2 selama $>10$ tahun. Hal ini sejalan dengan penelitian yang dilakukan oleh Maliya pada tahun 2011 di RS PKU Muhamadiyah Yogyakarta yang dimana hasilnya menunjukkan bahwa status gingiva berdasarkan lamanya menderita pada pasien DM tipe 2 paling banyak dijumpai pada penderita yang mengalami DM tipe 2 selama $>10$ tahun $^{16}$.

Status gingiva berdasarkan kontrol gula darah (HbA1c) yang paling banyak ditemui yaitu pada penderita DM tipe 2 yang memiliki kontrol gula darah buruk (>9\%) dengan total 50 subjek penelitian. Hal ini sebanding dengan penelitian yang dilakukan oleh Nandya pada tahun 2012 di Puskesmas Pucang Sewu Surabaya yang dimana menyatakan bahwa hasil pemeriksaan status gingiva berdasarkan kontrol gula darah (HbA1c) pada penderita DM tipe 2 paling banyak ditemui pada pasien dengan kontrol gula darah buruk (>9\%) akan tetapi dengan total responden yang lebih sedikit yaitu 35 responden $^{17}$.

\section{SIMPULAN}

Berdasarkan hasil penelitian dan pengolahan data dapat disimpulkan bahwa status gingiva pada penderita Diabetes Melitus tipe 2 yang dirawat jalan di Poliklinik Interna Rumah Sakit Umum GMIM Pancaran Kasih Manado yang dihitung berdasarkan indeks gingiva paling banyak menunjukkan gingivitis berat.

\section{SARAN}

Diharapkan dapat dijadikan sebagai masukan dan pertimbangan pemerintah dalam mencanangkan program untuk mengoptimalkan upaya perawatan kesehatan gigi dan mulut, dan bagi penderita DM tipe 2 agar lebih meningkatkan pola hidup sehat guna menormalkan kadar glukosa darah sehingga dapat mengurangi terjadinya diabetes, serta lebih memperhatikan dan menjaga kebersihan gigi dan mulut terutama kesehatan gingivanya.

\section{DAFTAR PUSTAKA}

1. Darmowidjojo B, Yunir E, Ilyas EI, Rahajeng E, Semiardji G, Subekti I, dkk. Hidup Sehat dengan Diabetes. Jakarta: Balai Penerbit FKUI; 2007.

2. Hasdianah HR. Mengenal Diabetes Melitus. Yogyakarta: Nuha Medika; 2012: 1-2

3. Perkumpulan Endokrinologi Indonesia. Konsensus Pengelolaan dan Pencegahan Diabetes Melitus Tipe 2 di Indonesia 2011. Jakarta: PB.PERKENI; 2011

4. Riset Kesehatan Dasar (RISKESDAS) 2011. Laporan Penelitian. Departemen Kesehatan Republik Indonesia; 2008. p.130-2

5. Hamsafir E. Pentingnya Kesehatan Rongga Mulut pada Penderita Diabetes. [online]. 2011 Juli 25 [cited 2014 Mar 1]

6. Limbong R. Hubungan HbA1c sebagai Parameter Kontrol Gula Darah DM Tipe 2 dengan Retinopati Diabetik. USU e-Repository 2011; p.1-2

7. Setyawati. Diabetes Melitus VS Manifestasi Oralnya. [online]. 2011 Mei 13 [cited 2014 Mar 2]

8. Ratih D, Anggraini L. Kebersihan Mulut Penting untuk Penderita Diabetes Melitus. [online]. 2011 Feb 22 [cited 2014 Mar 1] 
9. Hariyanto D. Hubungan Sakit Gigi dan Diabetes. [online]. 2008 Aug 16 [cited 2014 Mar 2]

10.Hussain A. Hubungan antara Diabetes Melitus dengan Penyakit Periodontal. [skripsi online]. 2012 [cited 2014 Mar 2]

11.Windiyarti A. Hubungan Karakteristik Individu, Kontrol Diabetes Melitus serta Kebersihan Gigi dan Mulut Dengan Keparahan Gingivitis pada Penderita Diabetes Melitus Tipe 2 (Studi pada Pasien Rawat Jalan Badan Rumah Sakit Umum Daerah Banjarnegara). UNDIP 2003; 32: Abstrak

12. Ruhadi I. Aini I. Kekambuhan Gingivitis Hiperplasi Setelah Gingivektomi (Reccurent of Hyperplastic Gingivitis After Gingivectomy). Maj. Ked. Gigi. (Dent.J) 2005; 38(3): p.108-10.
13. Kartika K. Gambaran Status Gingiva pada Pasien DM Tipe 2 di Rumah Sakit Semarang. Gigi Jurnal; 2006

14.Awad N. Gambaran Faktor Risiko Pasien Diabetes Melitus Tipe 2 di Poliklinik Endokrin RSU Prof. Dr. R. D. Kandou Manado. Ejournal; 2011. h. 48

15.Winardi N. Keparahan dari Penyakit Periodontal pada Pasien Dewasa yang Menderita Diabetes Melitus dengan Tipe Diabetesnya. Gigi Jurnal; 2011

16. Maliya A. Gambaran Status Gingiva pada Pasien Diabetes Melitus tipe 2 di RS PKU Muhamadiyah Yogyakarta. UMS Publikasi Ilmiah; 2011

17.Nandya. Hubungan Status Periodontal dengan Diabetes Melitus tipe 2 di Puskesmas Pucang Sewu Surabaya. Ejournal Airlangga; 2012 